\title{
Polymorphonuclear Leukocyte Adherence and Chemotaxis in Stressed and Healthy Neonates
}

\author{
PETER J. KRAUSE, VICTOR C. HERSON, JOCELYNE BOUTIN-LEBOWITZ, \\ LEONARD EISENFELD, CHARLOTTE BLOCK, TINA LOBELLO, AND \\ EUFRONIO G. MADERAZO \\ Divisions of Pediatric Infectious Diseases and Neonatology, Department of Pediatrics and the Medical Research \\ Laboratory, Division of Infectious Diseases, the Department of Medicine, Hartford Hospital, Hartford, \\ Connecticut and the University of Connecticut School of Medicine, Farmington, Connecticut 06115
}

\begin{abstract}
Defects in polymorphonuclear neutrophil (PMN) adherence and chemotaxis in neonates are thought to be an important cause of their increased susceptibility to overwhelming bacterial infection. Few studies of these functions have been carried out in stressed neonates who are at even greater risk of infection. PMN adherence and chemotaxis were examined in 33 stressed neonates with acute lower respiratory illness, 13 healthy neonates, and 43 healthy adults using whole blood PMN adherence and chemotaxis assays. PMN chemotaxis was significantly decreased in stressed neonates (locomotion index of 38.4 $\pm 9.7 \mu \mathrm{m})$ compared with that of healthy neonates $(48.9 \pm$ $12.8 \mu \mathrm{m}, p<0.01)$ or adults $(61.6 \pm 11.9 \mu \mathrm{m}, p<0.001)$. PMN chemotaxis was studied during illness and recovery in 13 of the 33 stressed neonates and showed significant improvement during recovery $(41.6 \pm 9.9$ and 53.2 \pm 11.9 $\mu \mathrm{m}$, respectively, $p=0.012$ ). PMN adherence was decreased in stressed neonates $(1.4 \pm 1.6 \%)$ compared with that of adults $(12.3 \pm 11.4 \%, p<0.01)$ but was similar to that of healthy neonates $(1.1 \pm 1.4 \%)$. These findings suggest that further impairment of PMN chemotaxis in stressed neonates helps account for their increased susceptibility to overwhelming bacterial infection. (Pediatr Res 20: $296-300,1986$ )
\end{abstract}

\section{Abbreviations}

PMN, polymorphonuclear neutrophil $\mathbf{L I}_{20}$, locomotion index

Bacterial infections are a major cause of morbidity and mortality in newborn infants primarily because of immaturity of their host defense mechanisms $(1,2)$. Neutrophils (PMNs) are the major cellular elements which defend against bacterial invasion. They respond to infection by adhering to vascular endothelium, moving toward the site of infection along a chemotactic gradient (chemotaxis) and killing ingested bacteria. The functional capacity of neonatal PMNs have been carefully studied and although results are not entirely consistent, PMN adherence (3-5) and chemotaxis (6-8) appear to be depressed in healthy neonates compared with that of adults while phagocytosis and microbial killing $(9-12)$ are intact. In studies of neonates with underlying illness or stress, PMN phagocytosis has been found to be normal $(11-15)$ while microbial killing has been found to

Received June 17. 1985; accepted November 26, 1985

Correspondence Peter J. Krause, M.D., Department of Pediatrics, Hartford Hospital, Hartford, CT 06115.

This study was supported in part by Hartford Hospital Research Free Funds. be decreased $(11-13,15,16)$. There have been few studies of PMN adherence and chemotaxis in stressed neonates (17). Since further impairment in these functions could help explain the increased susceptibility of stressed neonates to overwhelming bacterial infection, we prospectively studied PMN adherence and chemotaxis in healthy newborn infants and those with respiratory distress syndrome, pneumonia, and other cardiorespiratory illnesses.

\section{MATERIALS AND METHODS}

Subjects. Blood was obtained from 33 stressed neonates with a median chronological age of 3 days (range 1-88 days) and median gestational age of 36 wk (range 25-43 wk), 13 healthy neonates with a median chronological age of 6 days (range 3-88 days) and median gestational age of $36 \mathrm{wk}$ (range $27-42 \mathrm{wk}$ ) and 43 healthy adults. Three groups of stressed neonates were studied. Group I consisted of 16 neonates with respiratory distress syndrome, group II included nine neonates with pneumonia, and group III consisted of eight neonates with other cardiopulmonary illnesses including congenital heart disease with congestive heart failure $(n=4)$, meconium aspiration $(n=3)$ and severe birth anoxia $(n=1)$. All but three of the 33 stressed infants (two in group II and one in group III) required assisted ventilation during their acute illness and three died (all in group III).

One to $2 \mathrm{ml}$ of blood was obtained from indwelling arterial or venous catheters or from capillary (heel stick) sampling in neonates and venipuncture in adults. In every experiment blood was simultaneously obtained and PMN function tested in neonates and healthy adults. The PMN adherence and locomotory assays were begun within $20 \mathrm{~min}$ of blood collection. Informed consent to sample blood was obtained from all parents or adult subjects in accordance with Hartford Hospital Institutional Review guidelines.

PMN locomotory assay. PMN locomotory response was determined using a whole blood chemotaxis assay as previously described (18). In brief, blood was diluted with Medium 199 to 5 $\times 10^{5} \mathrm{PMNs} / 0.7 \mathrm{ml}$ and placed in the upper compartment of a transparent acrylic modified Boyden chamber (Ahlco Corp., Meriden, CT). The PMNs were allowed to penetrate a $13 \mathrm{~mm}$ diameter, $5 \mu \mathrm{m}$ pore size cellulose nitrate filter (Sartorius Filters, Hayward, CA) during a 90-min incubation in a humid $5 \% \mathrm{CO}_{2}$ atmosphere at $37^{\circ} \mathrm{C}$. In all experiments either Medium 199 or $3 \%$ zymosan activated normal adult serum in Medium 199 was placed in the bottom compartment of the Boyden chamber to test chemokinetic or chemotactic PMN responses, respectively. The filters were removed and soaked in $3 \%$ acetic acid to lyse erythrocytes and remove the hemoglobin stain. The filters were then fixed, stained, clarified, and mounted on slides. An automated microsectioning counting technique was used to determine the number of PMNs at $10 \mu \mathrm{m}$ increments from 20 to 120 
$\mu \mathrm{m}$ into the filter. Since we used a mixed leukocyte suspension, the first $20 \mu \mathrm{m}$ of the filter was not examined in order to avoid inclusion of monocytes and lymphocytes in the cell counts. The mean distance $(\mu \mathrm{m})$ migrated by the PMNs in 90 min of incubation time, or $\mathrm{LI}_{20}$, was then determined. A mean $\mathrm{LI}_{20}$ value of triplicate determinations was calculated for each blood sample. The coefficient of variation for this assay is 0.13 .

Cover glass adherence assay. Blood was tested using a whole blood cover glass adherence assay as previously described (4). In brief, blood was collected in chilled plastic tubes and placed on ice in order to prevent clotting prior to the assay procedure. The PMNs were incubated on cover slips for $45 \mathrm{~min}$ in a humid $5 \%$ $\mathrm{CO}_{2}$ atmosphere at $37^{\circ} \mathrm{C}$. Only a small fraction of the PMNs adhere to the cover slip with the whole blood assay and the number reaches near plateau at $45 \mathrm{~min}$ incubation time. After incubation, the clot was removed with forceps leaving a thin layer of PMNs adherent to the glass. The cover slip was gently rinsed with Medium 199, stained with Wright's stain, and mounted on a glass slide. Neutrophils were counted in every other field $(0.25 \times 0.25 \mathrm{~mm}$ grid $\times 400$ magnification $)$ along a horizontal and vertical diameter of the circle of adherent neutrophils. The percent PMN adherence value was then calculated as follows:

$\%$ PMN adherence

$$
=\frac{\frac{\text { PMNs counted }}{\text { area counted }} \times \text { area of entire circle }}{\text { PMNs in original } 20 \mu \mathrm{l} \text { sample }} \times 100
$$

The coefficient of variation for this assay is 0.29 .

Statistical analysis. Statistical significance of differences between groups was performed using the Student's two-tailed $t$ test. Linear regression was used to analyze the possible association between mean neonatal PMN chemotaxis and the percentage of immature PMNs in peripheral blood. A $p$ value of $<0.05$ was considered significant in all cases.

\section{RESULTS}

Chemotactic response. The PMN chemotactic response in 33 stressed neonates, 13 healthy neonates, and 43 healthy adults is shown in Figure 1. The mean PMN chemotactic $\mathrm{LI}_{20}$ value in stressed neonates $(38.4 \pm 9.7 \mu \mathrm{m})$ was significantly decreased compared with that of healthy neonates $(48.9 \pm 12.8 \mu \mathrm{m}, p<$ $0.01)$ or adults $(61.6 \pm 11.9 \mu \mathrm{m}, p<0.001)$. The mean chemokinetic $\mathrm{LI}_{20}$ response was also significantly decreased in stressed neonates $(33.4 \pm 9.1 \mu \mathrm{m})$ compared with that of adults $(46.1 \pm$

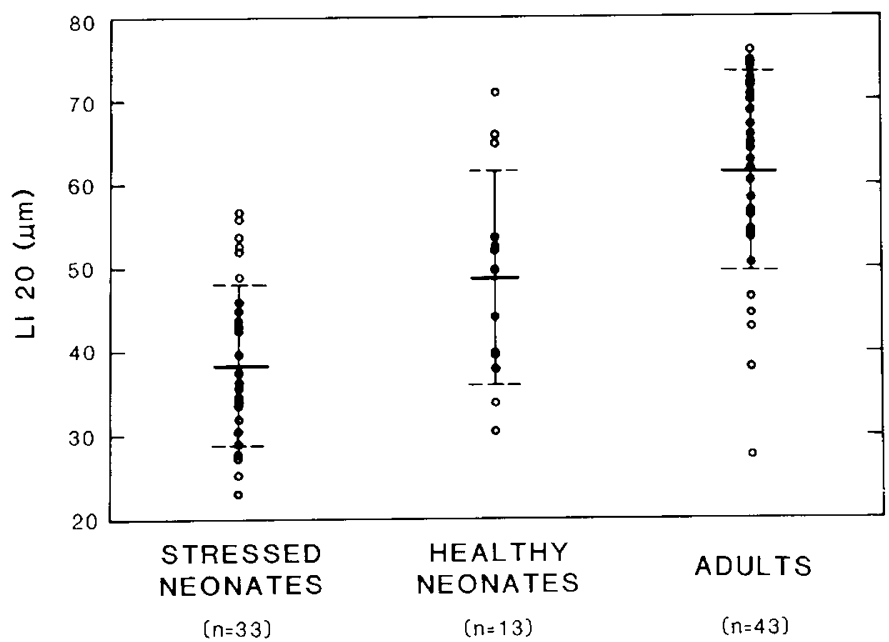

Fig. 1. PMN chemotaxis in stressed neonates, healthy neonates, and adults. The solid lines represent mean values. The hatched lines represent $\pm 1 \mathrm{SD}$.

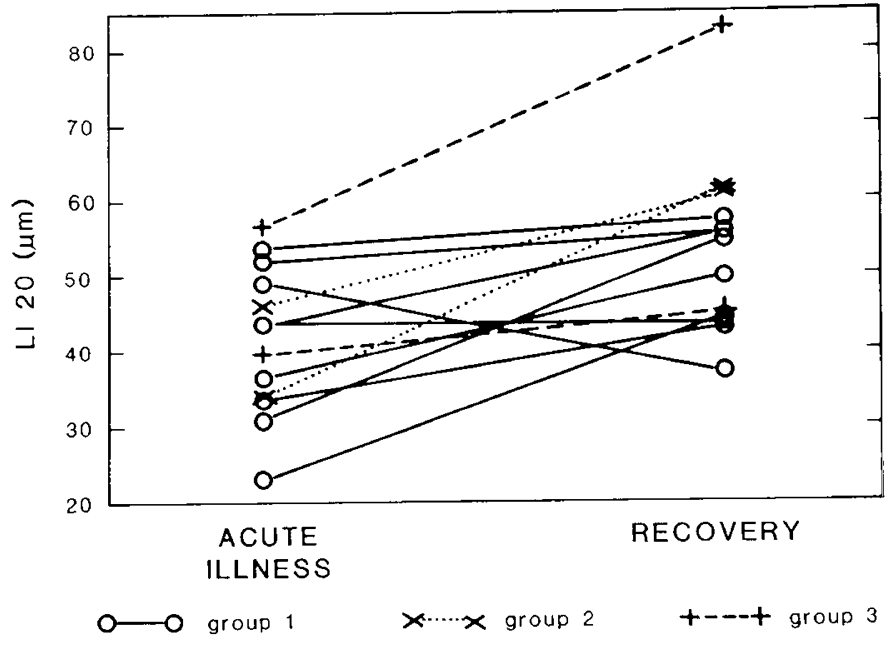

Fig. 2. PMN chemotaxis in neonates during acute illness and recovery.

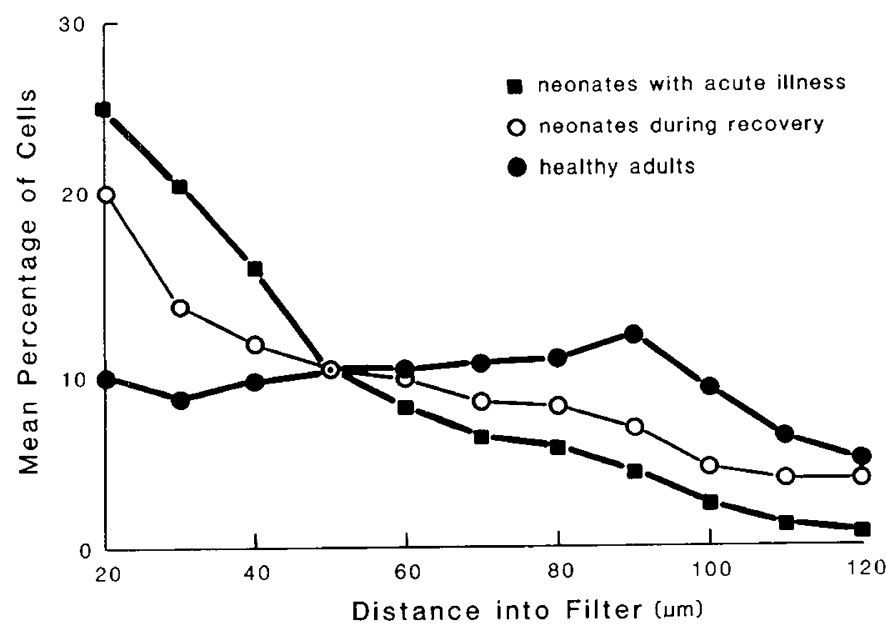

Fig. 3. The distribution of PMNs at different distances into the filter obtained from 13 neonates during acute illness and recovery and from 22 healthy adults. The PMNs were migrating toward a gradient of $3 \%$ zymosan activated normal adult serum during a 90-min incubation period.

$10.7 \mu \mathrm{m}, p<0.01)$ but not compared with that of healthy neonates $(35.2 \pm 4.7 \mu \mathrm{m})$. Mean chemotactic $\mathrm{LI}_{20}$ values were similar among the three stressed neonatal groups: group I (respiratory distress syndrome), $38.2 \pm 9.2 \mu \mathrm{m}$, group II (pneumonia), $39.2 \pm 10.8 \mu \mathrm{m}$, and group III (other cardiopulmonary), $38.0 \pm 9.1 \mu \mathrm{m}$. No difference in PMN chemotaxis was noted in 28 neonates with acute illness who had arterial blood catheter sampling $(38.4 \pm 9.9 \mu \mathrm{m})$ compared with four neonates who had capillary heel stick sampling $(39.3 \pm 6.0 \mu \mathrm{m})$.

The PMN chemotactic response was determined during the acute phase of illness and during recovery ( 3 to 11 days later) in nine neonates in group I and four neonates in groups II and III. The median chronological age of the total group was 3 days (range 1-81 days) during acute illness and 10 days (range 3-88 days) during convalescence. In all but two cases there was an increase in PMN chemotaxis during recovery with chemotactic $\mathrm{LI}_{20}$ values similar to those of healthy neonatal controls (median chronologic age was 5 days; range 3-88 days) as shown in Figure 2. Mean acute and convalescent $\mathrm{PMN}$ chemotactic $\mathrm{LI}_{20}$ values were $41.6 \pm 9.9$ and $53.2 \pm 11.9 \mu \mathrm{m}(p=0.012)$, respectively, for the stressed neonates compared with $48.9 \pm 12.8 \mu \mathrm{m}$ in the healthy, age-matched controls. 
Previous studies have indicated that depressed PMN locomotory responses may be due to changes in PMN subsets with varied functional characteristics. In order to compare PMN functional subpopulations in neonates and adults, we measured the number of PMNs at various depths in the micropore filter (Fig. 3) in the 13 neonates studied both during illness and recovery and in 22 simultaneously tested adults. We defined slow moving PMNs as those found from 20 to $50 \mu \mathrm{m}$ and fast moving PMNs as those found 60 to $120 \mu \mathrm{m}$ into the filter and calculated the percentage of each cell type in the study groups. Neonates with acute respiratory illness had a significantly higher percentage of slow moving PMNs $(71.3 \pm 6.4 \%)$ and lower percentage of fast moving PMNs $(28.3 \pm 2.7 \%)$ than during recovery $(55.4 \pm$ $4.5 \%, p<0.01$ and $44.4 \pm 2.3 \%, p<0.001$, respectively). Adults had a significantly lower percentage of slow moving PMNs (37.4 $\pm 0.7 \%)$ and a higher percentage of fast moving PMNs $(67.5 \pm$ $2.5 \%$ ) than neonates during illness or recovery with $p$ values of $<0.001$ in both cases. Leukocyte differential counts were performed at the time of chemotactic testing in 12 of the 13 neonates studied during acute illness and in six of the 13 during convalescence. Although there was a higher mean percentage immature PMNs during acute illness $(11.9 \pm 10.7 \%)$ than during recovery $(5.0 \pm 5 \%)$, the difference was not statistically significant. Using linear regression analysis, there was no correlation between the percentage of immature PMNs (bands and metamyelocytes) and mean chemotactic $\mathrm{LI}_{20}$ in neonates with acute illness $(r=-0.37$, $p=0.24)$ or during recovery $(r=-0.43, p=0.34)$. These findings indicate that PMN locomotory responses in the 13 neonates studied during acute illness and recovery cannot be completely explained by the change in percentage of immature PMNs (bands and metamyelocytes) between the two groups.

Adherence response. There was no significant difference between mean PMN adherence values of stressed neonates $(1.4 \pm$ $1.6 \%)$ and healthy neonatal controls $(1.1 \pm 1.4 \%)$. Both values were significantly decreased compared with that of adults (12.3 $\pm 11.4 \%, p<0.01)$. There was no significant difference in PMN adherence between stressed neonates during acute illness ( $1.2 \pm$ $1.4 \%)$ and recovery $(1.0 \pm 2.1 \%)$.

Clinical correlates of the PMN chemotactic response. In an attempt to identify possible causes of decreased PMN chemotaxis in the stressed neonatal groups, the effects of 11 clinical conditions on chemotaxis were analyzed. These conditions are listed

\section{Table 1. Common clinical categories having no significant*} effect on PMN chemotaxis

\begin{tabular}{|c|c|}
\hline $\operatorname{Sex}$ & Male (19), $\dagger$ female $(14)$ \\
\hline Gestation & $\begin{array}{l}<32 \text { wk }(10), \geq 32 \text { wk }(23) \\
<38 \text { wk }(14), \geq 38 \text { wk }(19)\end{array}$ \\
\hline Birth wt & $\begin{array}{l}<2500 \mathrm{~g}(10), \geq 2500 \mathrm{~g}(23) \\
\quad<1500 \mathrm{~g}(9), \geq 1500 \mathrm{~g}(24)\end{array}$ \\
\hline Pregnancy & $\begin{array}{l}\text { Use of steroids (2), no steroids } \\
\text { (31) }\end{array}$ \\
\hline \multirow[t]{2}{*}{ Delivery } & $\begin{array}{l}\text { Cesarean section (3), vaginal } \\
\text { delivery ( } 30)\end{array}$ \\
\hline & $\begin{array}{l}\text { Local anaesthesia (18), general } \\
\text { anaesthesia (6) }\end{array}$ \\
\hline Apgar score & $\begin{array}{l}<7(14), \geq 7(19) \text { at } 1 \mathrm{~min} ;<7 \\
(10), \geq 7(23) \text { at } 5 \mathrm{~min}\end{array}$ \\
\hline Postnatal age when tested & $\begin{array}{l}<1 \text { day }(10), \geq 1 \text { day }(23) ;<1 \\
\quad \text { wk }(14), \geq 1 \text { wk }(19)\end{array}$ \\
\hline \multirow[t]{3}{*}{ Neonatal therapy } & $\begin{array}{l}\text { Use of antibiotics (30); no an- } \\
\text { tibiotics (3) }\end{array}$ \\
\hline & $\begin{array}{l}\text { Use of calcium }(8), \text { no cal- } \\
\text { cium }(25)\end{array}$ \\
\hline & $\begin{array}{l}\text { Use of assisted ventilation for } \\
0 \text { days (3), } 1-3 \text { days (2), } \geq 3 \\
\text { days (28). }\end{array}$ \\
\hline
\end{tabular}

$* p>0.05$ by two tailed $t$ test.

$\dagger$ Number in parentheses refers to the number of subjects. in Table 1. Mean PMN chemotactic $\mathrm{LI}_{20}$ values were compared in stressed and healthy neonates with and without each condition. No condition was associated with a significant decrease in PMN chemotaxis. For example, the mean PMN chemotactic $\mathrm{LI}_{20}$ values for stressed $[36.8 \pm 9.0 \mu \mathrm{m}(n=10)]$ and healthy neonates $[48.8 \pm 5.5 \mu \mathrm{m}(n=5)]$ who weighed less than $2500 \mathrm{~g}$ at birth were not significantly different than values for stressed $[39.1 \pm 9.6 \mu \mathrm{m}(n=23, p>0.05)]$ and healthy neonates $[49.0$ $\pm 12.1 \mu \mathrm{m}(n=8, p>0.05)]$ with a birth weight of $2500 \mathrm{~g}$ or greater. There was also no significant difference in the mean PMN $\mathrm{LI}_{20}$ chemotactic values in the three infants who died and the 30 who survived or in the three infants who did not require assisted ventilation and the 30 who did.

\section{DISCUSSION}

The results of this study clearly show that PMN chemotaxis was decreased in healthy neonates compared with that of adults and was further impaired in neonates with acute respiratory illness. The magnitude of PMN chemotactic impairment in stressed compared with healthy neonates was similar to that of healthy neonates compared with adults. Several in vitro studies in healthy human neonates $(3,6-8)$, have shown decreased PMN motility compared with that of adults. The results of two previous studies of PMN chemotaxis in smaller groups of stressed neonates were also similar to ours. Decreased PMN chemotaxis was noted in premature infants with sepsis (19) and infants of diabetic mothers (20) compared with that of healthy neonates. These data suggest that impairment of PMN motility in neonates is an important cause of their increased susceptibility to overwhelming bacterial infection. They also indicate that a further decrease of PMN motility in stressed neonates helps explain the even greater morbidity and mortality from infection in these infants compared with those who are healthy.

The mechanisms responsible for impaired PMN chemotaxis in the stressed neonates are unclear. The whole blood chemotaxis assay used in this study approximates in vivo conditions more closely than separated cell assays, however, it is less useful for determination of the relative effects of serum and cellular factors on PMN chemotaxis. Previous studies in healthy neonates have identified both humoral $(6,8,21-23)$ and cellular $(3-5,24-26)$ abnormalities which could explain decreased PMN chemotaxis in neonates compared with adults. Serum defects have included decreased levels of complement $(8,21-22)$ and the presence of a chemotactic factor inactivator $(8,23)$. Cellular defects have included decreased membrane receptors for chemoattractants (24), impaired microtubule assembly (25), decreased adherence (3-5), and decreased membrane deformability (26). Decreased PMN chemotaxis in the stressed neonates might have been due to further impairment in any one or more of these defects or might have resulted from other defects such as the presence of a cell directed inhibitor or activated complement fragments. There have been a number of studies of PMN chemotaxis in stressed populations. In adults with severe bacterial infection, decreased PMN chemotaxis has been described and has been attributed to cellular (27-29) and humoral (30) factors. Interestingly, studies of older children and adults with skin or nonlife-threatening systemic bacterial infections showed an increase in PMN chemotaxis (31-33). Laurenti et al. (19) studied neonates with surface infection and sepsis. Those with surface infection had an increase in PMN chemotaxis while those with sepsis had impaired PMN chemotaxis. Serum from neonates with sepsis did not have an inhibitory effect on chemotaxis of PMNs from healthy preterm infants and adults suggesting a cellular cause for decreased PMN chemotaxis in these septic neonates.

Recent attention has focused on the role of PMN adherence in decreased neonatal PMN chemotaxis (3-5). PMN adherence is not only important in PMN margination to vascular endothelium but also provides anchoring of the cell for forward movement. Several children with a PMN membrane glycoprotein 
deficiency that prevents normal adherence have been described $(34,35)$. These children have markedly decreased PMN chemokinesis and chemotaxis and recurrent bacterial and fungal infections. In a more recent study, decreased PMN membrane surface expression of glycoprotein p150, 95 in response to f-Met-LeuPhe was demonstrated in neonatal compared with adult PMNs. It was suggested that decreased "up regulation" of adhesive glycoproteins in neonates could account for the decrease in "functionally linked" PMN adherence and chemotaxis (36). The results of previous studies of PMN adherence in healthy neonates have shown a decrease $(3-5)$, no difference $(8,37)$, or an increase (38) compared with that of adults. Anderson et al. (3) found no difference in unstimulated PMN adherence between healthy neonates and adults, however, there was augmented adherence in the presence of the chemoattractant f-Met-Leu-Phe with adult but not neonatal PMNs. Harris et al. (5) studied PMN adherence in healthy neonates and those with acute respiratory illness using a separated PMN glass cover slip assay. They found no difference in PMN adherence between the two neonatal groups at $5 \mathrm{~min}$ incubation but an increase in PMN adherence in stressed compared with healthy neonates when PMNs were incubated for 10 or $20 \mathrm{~min}$. The healthy and stressed neonates had markedly decreased PMN adherence compared with that of adults which was attributed to diminished amounts of PMN fibronectin. The results of our study showed a decrease in PMN adherence in stressed and healthy neonates compared with that of adults using a whole blood cover slip adherence assay. No difference was found in PMN adherence between stressed and healthy neonates, although a more sensitive PMN adherence assay might have detected differences between the two groups. Discordant results in studies of PMN adherence in neonates are thought to be due to differences in experimental conditions including the method of PMN separation, the type of adherent surface used, the presence of chemoattractants, the incubation time during which PMNs adhere, and the method of removing "nonadherent" PMNs. Despite these differences we believe the bulk of evidence indicates that there is a significant decrease in the PMN adherence of healthy neonates compared with that of adults. Differences in PMN adherence between neonates with acute lower respiratory illness and healthy neonates, if present, appear to be more subtle and probably have less of an effect on PMN migration, diapedesis, and chemotaxis.

Alteration in PMN functional subpopulations in the circulation is another possible mechanism which could explain the difference in PMN chemotaxis between stressed and healthy neonates. Gallin (39) has suggested that changes in PMN function in some infectious and noninfectious inflammatory illnesses may result from alterations in PMN subpopulations. In the present study, calculation of the number of PMNs at different depths in the micropore filter suggests that there is PMN functional heterogeneity in neonates and adults. It is unclear whether the observed chemotactic heterogeneity represents true subpopulations of cells derived from distinct stem cells or maturational differences within a common cell line which cannot be distinguished by light microscopy. Regardless of the source, it appears that there may have been a shift to less functional PMN subpopulations in neonates during acute respiratory illness. Recent studies have shown that neonates and adults with various types of noninfectious respiratory illness, including respiratory distress syndrome, have an accumulation of PMNs in the lung $(40,41)$. It is thus possible that during acute respiratory illness, motile PMNs moved from the circulation to the lungs, leaving behind less motile PMNs. During recovery one would expect a decrease in PMN movement to the lung including the more motile PMN subpopulation. The average distance traveled by the PMNs during recovery $\left(\mathrm{LI}_{20}\right)$ would thus be expected to be greater than during acute illness.

The observed changes in PMN chemotactic subpopulations might be attributed to changes in the percentage of immature PMNs since previous studies indicate that immature PMNs are slower than mature PMNs (8). Our data suggest that this could not fully account for the PMN functional subpopulation changes observed in our patients. Although there was a higher percentage of immature PMNs in neonates with acute respiratory illness than during recovery, the difference was not statistically significant. Furthermore, variation in the chemotactic response in neonates with acute respiratory illness did not correlate with the percentage of immature PMNs. In recent studies using a monoclonal antibody (31D8) whose heterogeneous binding to PMNs correlates with membrane depolarization, NBT reduction, and chemotaxis $(42,43)$, we noted significant differences between $31 \mathrm{D} 8$ binding to neonatal and adult PMNs (44). Compared with adults, neonates had a lower percentage of PMNs that tightly bound 31D8 (more motile cells) and a higher percentage of PMNs that weakly bound 31D8 (less motile cells). No significant differences in the percentage of immature PMNs were noted between the two 31D8 subpopulations. These data indicate that mature appearing PMNs are functionally heterogeneous and this heterogeneity may help explain changes in PMN chemotaxis in neonates during acute respiratory illness and recovery.

In summary, studies of PMN adherence and chemotaxis in neonates have shown that both functions are significantly decreased compared with that of adults. PMN chemotaxis, but not PMN adherence, was further impaired in neonates with infectious and noninfectious pulmonary disease. The cause of decreased PMN chemotaxis during acute respiratory illness in neonates is unclear but may be related in part to alterations in PMN functional subpopulations. Decreased PMN chemotaxis in stressed neonates may contribute to their increased susceptibility to overwhelming bacterial infection.

Acknowledgments. The authors thank Dr. Charles Woronick for advice, Linda Pontius for technical assistance, and Gail Frese for help in preparation of the manuscript.

\section{REFERENCES}

. Gotoff SP 1974 Neonatal immunity. J Pediatr 85:149-154

2. Miller ME, Stiehm ER 1983 Immunology and resistance to infection. In: Remington JS, Klein JO (eds) Infectious Diseases of the Fetus and Newborn Infant. WB Saunders Company, Philadelphia, pp 27-68

3. Anderson DC, Hughes BJ, Smith CW 1981 Abnormal mobility of neonatal polymorphonuclear leukocytes. J Clin Invest 68:863-874

4. Krause PJ, Maderazo EG, Scroggs M 1982 Abnormalities of neutrophil adherence in newborns. Pediatrics 69:184-187

5. Harris MC, Levitt J, Douglas SD, Gerdes JS, Polin RA 1985 Effect of fibronectin on adherence of neutrophils from newborn infants. $\mathrm{J}$ Clin Microbiol 21:243-246

6. Miller ME 1971 Chemotactic function in the human neonate: humoral and cellular aspects. Pediatr Res 5:487-492

7. Klein RB, Fischer TJ, Gard SE, Biberstein M, Rich KC, Stiehm ER 1977 Decreased mononuclear and polymorphonuclear chemotaxis in human newborns, infants and young children. Pediatrics 60:467-472

8. Boner A, Zeligs BJ, Bellanti JA 1982 Chemotactic responses of various differentiational stages of neutrophils from human cord and adult blood. Infect Immun 35:921-928

9. Forman ML, Stiehm ER 1969 Impaired opsonic activity but normal phagocytosis in low-birth-weight infants. N Engl J Med 281:926-931

10. Dossett JH, Williams RC, Quie PG 1969 Studies on interaction of bacteria, serum factors and polymorphonuclear leukocytes in mothers and newborns. Pediatrics 44:49-57

11. Shigeoka AO, Santos JI, Hill HR 1979 Functional analysis of neutrophil granulocytes from healthy, infected and stressed neonates. J Pediatr 95:454460

12. Wright WC, Ank BJ, Herbert J, Stiehm ER 1975 Decreased bactericidal activity of leukocytes of stressed newborn infants. Pediatrics 56:579-584

13. Mills EL, Thompson T, Björkstén B, Filipovich D, Quie PG 1979 The chemilumenescence response and bactericidal activity of polymorphonuclear neutrophils from newborns and their mothers. Pediatrics 63:429-434

14. Harris MC, Stroobant J, Cody CS, Douglas SD, Polin RA 1983 Phagocytosis of group B streptococcus by neutrophils from newborn infants. Pediatr Res 17:358-361

15. Shigeoka AO, Charette RP, Wyman ML, Hill HR 1981 Defective oxidative metabolic responses of neutrophils from stressed neonates. J Pediatr 98:392398

16. Stroobant J, Harris MC, Cody CS, Polin RA, Douglas SD 1984 Diminished bactericidal capacity for group B streptococcus in neutrophils from "stressed" and healthy neonates. Pediatr Res 18:634-637 
17. Speer CP, Johnston RB Jr. 1984 Phagocyte function. In: Ogra PL (ed) Neonatal Infections, Nutritional and Immunologic Interactions. Grune and Stratton, Inc, Orlando, pp 21-36

18. Krause PJ, Pock RM, Woronick CL, Maderazo EG 1983 Simplified micropore filter assay of neutrophil migration using whole blood. J Infect Dis 148:881 885

19. Laurenti F, Ferro R, Marzetti G, Rossini M, Bucci G 1980 Neutrophil chemotaxis in preterm infants with infections. J Pediatr 96:468-470

20. Mohandes AE, Touraine JL, Osman M, Salle B 1982 Neutrophil chemotaxis in infants of diabetic mothers and in preterms at birth. J Clin Lab Immunol 8:117-120

21. Edwards MS, Buffone GJ, Fuselier PA, Weeks JL, Baker CJ 1983 Deficient classical complement pathway activity in newborn sera. Pediatr Res 17:685688

22. Fireman P, Zuchowski DA, Taylor PM 1969 Development of human complement system. J Immunol 103:25-31

23. Tannous R, Spitzer RE, Clarke WR, Goplerud CP, Cavendar-Zylich N 1982 Decreased chemotactic activity in activated newborn plasma. $J$ Lab Clin Med 99:33 [-341

24. Nunoi H, Endo F, Chikazawa S, Nanikawa T, Matsuda I 1983 Chemotactic receptor of cord blood granulocytes to the synthesized chemotactic peptide N-formyl-methionyl-leucyl-phenylalanine. Pediatr Res 17:57-60

25. Anderson DC, Hughes BJ, Wible LJ, Perry GJ, Smith CW, Brinkley BR 1984 Impaired motility of neonatal PMN leukocytes: relationship to abnormalities of cell orientation and assembly of microtubules in chemotactic gradients. $\mathrm{J}$ Leukocyte Biol 36:1-15

26. Miller ME 1979 Cell elastimetry in the study of normal and abnormal movement of human neutrophils. Clin Immunol Immunopathol 14:502-510

27. McCall CE, Caves J, Cooper R, deChatelet L 1971 Functional characteristics of human toxic neutrophils. J Infect Dis 124:68-75

28. Frei PC, Baisero MH, Ochsner M 1974 Chemotaxis of human polymorphonuclears in vitro: critical study of clinical interpretations. Antibiot Chemother 19:350-361

29. Althaus D. Keller HU, Hess MW, Cottier H 1980 Impaired neutrophil locomotion during acute bacterial infections. Int Arch Allergy Appl Immunol 61:321-328

30. Link AS Jr, Bass DA, McCall CE 1979 Altered neutrophil migration during bacterial infection associated with a serum modulator of cellular motility $\mathbf{J}$ Infect Dis 140:517-526

31. Hill HR, Gerrard JM. Hogan NA, Quie PG 1974 Hyperactivity of neutrophil leukotactic responses during active bacterial infection. J Clin Invest 53:9961002

32. Cates KL, Quie PG 1979 Neutrophil chemotaxis in patients with Staphylococcus aureus furunculosis. Infect Immun 26:1004-1008

33. Hill HR, Kaplan EL, Dajani AS, Wannamaker LW, Quie PG 1974 Leukotactic activity and reduction of nitroblue tetrazolium by neutrophil granulocytes from patients with streptococcal skin infection. J Infect Dis 129:322-326

34. Crowley CA, Curnutte JT, Rosin RE, Andre Schwartz J, Gallin JI, Klempner M, Snyderman R, Southwick FS, Stossel TP, Babior BM 1980 An inherited abnormality of neutrophil adhesion. N Engl J Med 302:1163-1168

35. Anderson DC, Schmalstieg FC, Arnaout MA, Kohl S, Tosi MF, Dana N, Buffone GJ, Hughes BJ, Brinkley BR, Dickey WD, Abramson JS, Springer T, Boxer LA, Hollers JM, Smith CW 1984 Abnormalities of polymorphonuclear leukocyte function associated with a heritable deficiency of high molecular weight surface glycoproteins (GP 138): common relationship to diminished cell adherence. J Clin Invest 74:536-551

36. Anderson DC, Freeman KB, Hughes BJ, Buffone GJ 1985 Secretory determinants of impaired adherence and motility of neonatal PMNs. Pediatr Res 19:880(abstr)

37. Fontan G, Lorente F, Rodriquez MG, Ojeda JA 1979 Granulocyte adherence in umbilical cord blood. J Pediatr 94:969-970

38. Rao S, Olesinski R, Doshi U, Vidyasagar D 1981 Granulocyte adherence in newborn infants. $J$ Pediatr 98:622-624

39. Gallin JI 1984 Human neutrophil heterogeneity exists, but is it meaningful? Blood 63:977-983

40. Ogden BE, Murphy S, Saunders GC, Johnson JD 1983 Lung lavage of newborns with respiratory distress syndrome. Prolonged neutrophil influx is associated with bronchopulmonary dysplasia. Chest $5: 31 \mathrm{~S}-33 \mathrm{~S}$

41. Zimmerman GA, Renzetti AD, Hill HR 1983 Circulating polymorphonuclear leukocyte activity in patients with the adult respiratory distress syndrome. Implications for pulmonary vascular injury. Chest 5:87S-89S

42. Seligmann B, Malech HL, Melnick DA, Gallin JI 1985 An antibody to a subpopulation of neutrophils demonstrates antigenic heterogeneity which correlates with response heterogeneity. Trans Assoc Am Phys 47:319-324

43. Seligmann B, Malech HL, Melnick DA, Gallin JI 1985 An antibody binding to human neutrophils demonstrates antigenic heterogeneity detected early in myeloid maturation which correlates with functional heterogeneity of mature neutrophils. J Immunol 135:2647-2653.

44. Krause PJ, Kosciol C, Pontius LT, Malech HL 1985 Neutrophil heterogeneity in neonates and adults. Pediatr Res 19:1001(abstr) 